\title{
Increased expression of G9A contributes to carcinogenesis and indicates poor prognosis in hepatocellular carcinoma
}

\author{
JIAN QIN $^{1 *}$, QINGYUN LI $^{1 *}$, ZHI ZENG $^{2}$, PING WU $^{3}$, YANPING JIANG $^{4}$, TAO LUO $^{5}$, \\ XIANG JI ${ }^{3}$, QIUPING ZHANG ${ }^{3}$, YARONG HAO ${ }^{6}$ and LANG CHEN $^{3}$ \\ ${ }^{1}$ Central Laboratory; ${ }^{2}$ Department of Pathology, Renmin Hospital of Wuhan University, Wuhan, Hubei 430060; \\ ${ }^{3}$ Department of Immunology, School of Basic Medical Sciences, Wuhan University, Wuhan, Hubei 430071; \\ ${ }^{4}$ Department of Gynecology and Obstetrics, Renmin Hospital of Wuhan University, Wuhan, Hubei 430060; \\ ${ }^{5}$ Department of Anesthesiology, Peking University Shenzhen Hospital, Shenzhen, Guangdong 518036; \\ ${ }^{6}$ Department of Geriatric, Renmin Hospital of Wuhan University, Wuhan, Hubei 430060, P.R. China
}

Received December 8, 2015; Accepted May 23, 2017

DOI: $10.3892 / \mathrm{ol} .2018 .8572$

\begin{abstract}
Euchromatic histone-lysine N-methyltransferase (G9A), the primary histone methyltransferase for histone $\mathrm{H} 3$ Lys $^{9}$, has been identified to be upregulated in numerous types of cancer. The aim of the present study was to analyze the clinical significance of G9A, and preliminarily explore its function in hepatocellular carcinoma (HCC). An increased expression level of G9A was demonstrated in the HCC samples and also in 5 publically available datasets. By analyzing GSE14520, it was revealed that its expression level was significantly associated with serum $\alpha$-fetoprotein level of patients with HCC, and may serve as a potential prognostic indicator for patients with multinodular HCC. Bioinformatics tools were utilized to predict the potential function of G9A, and the results indicated that G9A may modulate gene sets involved in RNA processing and DNA replication. G9A inhibition may suppress cell proliferation by arresting cells in G1 phase and increasing the expression level of microtubule-associated protein light chain $3 \beta$ (MAP1LC3B) in Huh7 and HepG2 cells. In addition, an inverse association between the expression of G9A and LC3B was demonstrated in HCC tumor samples in the publically available GSE14520 dataset, which indicated that G9A may also have the potential to regulate MAP1LC3B expression in HCC tumor tissues.
\end{abstract}

Correspondence to: Dr Jian Qin, Central Laboratory, Renmin Hospital of Wuhan University, 238 Jiefang Road, Wuhan, Hubei 430060, P.R. China

E-mail: qinjian621@163.com

Dr Lang Chen, Department of Immunology, School of Basic Medical Sciences, Wuhan University, 185 Donghu Road, Wuhan, Hubei 430071, P.R. China

E-mail: langchen@whu.edu.cn

*Contributed equally

Key words: euchromatic histone-lysine N-methyltransferase, proliferation, prognosis, LC3B, hepatocellular carcinoma
The results of the present study led to hypothesis that the G9A expression level may be of assistance in diagnosing HCC, and be a potential therapeutic target for HCC. The results provided novel evidence for additional understanding of the crucial role of G9A in tumorigenesis.

\section{Introduction}

Aberrant epigenetic regulations have been identified in various types of cancer and a number of types of human disease (1). The cancer epigenome is characterized by genome-wide changes in DNA methylation and altered histone modification patterns (1). The global pattern of histone modifications may serve as a predictor of the risk of recurrence of human cancer (2,3). Epigenetics has become a common focus in studies investigating the pathogenesis of many types of human diseases, particularly in cancer. Hepatocellular carcinoma (HCC) is one of the most common types of neoplasm, and the most frequent cause of cancer-associated mortality $(4,5)$. Previous evidence has suggested that epigenetic alterations are important for the pathogenesis of HCC. A whole-genome sequencing analysis of $27 \mathrm{HCCs}$ revealed that almost $50 \%$ of the tumors analyzed exhibited mutations in chromatin regulators, including histone methyltransferases (HMTs) (6). Previously, it has been demonstrated that histone H3 trimethylated at $\mathrm{Lys}^{27}$ and histone $\mathrm{H} 3$ trimethylated at Lys ${ }^{4}$ may serve as prognostic markers and therapeutic targets in HCC (7). These results indicate that aberrant histone methylation may be involved in the carcinogenesis of HCC, but the functions of HMT and histone demethylase (HDM) in the pathogenesis of HCC require additional study.

Euchromatic histone-lysine N-methyltransferase (G9A) is the primary HMT for mono- and dimethylation of histone $\mathrm{H} 3$ Lys $^{9}$ (H3K9) in vivo (8). Among various well-studied histone methylations, H3K9 methylation is thought to be associated with gene repression (9). Previously, G9A has been identified to serve critical roles in various biological progresses such as behavior plasticity, lymphocyte development, stem cell differentiation and tumor cell growth (10-15). It has been suggested that the expression level of G9A is increased in numerous 
types of cancer compared with their corresponding normal tissues, including melanoma, lung cancer, neuroblastoma, leukemia and HCC (15-17). Specifically decreasing G9A expression levels or inhibiting its activity may inhibit metastasis in lung cancer and decrease cell proliferation by inducing autophagy in colon cancer, breast cancer and neuroblastoma cells $(15,18,19)$.

In the present study, the clinical significance of G9A expression and its potential function in HCC progression was investigated. The increased G9A expression level in HCC was additionally confirmed in 5 publicly available datasets and the HCC samples. By analyzing GSE14520, it was identified that increased expression of G9A may serve as an indicator for a poor prognosis in multinodular HCC. Gene set enrichment analysis (GSEA) was utilized to predict the potential function of G9A, and the results demonstrated that G9A may modulate gene sets involving RNA processing and DNA replication. G9A inhibition significantly decreased proliferation by arresting cells in G1 phase and increased microtubule-associated protein light chain 3 $\beta$ (MAP1LC3B) expression levels in Huh7 and HepG2 cell lines. An inverse association between the expression of G9A and MAP1LC3B was identified in HCC tumor samples in GSE14520, which indicated that G9A also had the potential to regulate MAP1LC3B expression in HCC tumor tissues. These results demonstrated that G9A was involved in the pathogenesis of HCC. These data may assist additional understanding of the crucial role of G9A in tumorigenesis.

\section{Materials and methods}

$H C C$ specimens and reverse transcription-quantitative polymerase chain reaction ( $R T-q P C R)$. HCC tumor specimens were obtained from the Department of Pathology, Renmin Hospital of Wuhan University (Wuhan, China). Informed consent was obtained from each patient prior to surgery. The research protocol was approved by Wuhan University School of Basic Medical Sciences Ethics Committee (Wuhan, China). The total RNA of each sample was extracted using TRIzol (Invitrogen; Thermo Fisher Scientific, Inc., Waltham, MA, USA), according to the manufacturer's protocol. RNA was reverse-transcribed into cDNA using a RevertAid First Strand cDNA Synthesis kit (Thermo Fisher Scientific, Inc.), according to the manufacturer's protocol. RT-qPCR was performed using the Takara Premix Ex Taq II 820 (Takara Bio, Inc., Otsu, Japan) according to the manufacturer's protocol on an ABI 7500 instrument (Applied Biosystems; Thermo Fisher Scientific, Inc.). Primer pairs for human $\beta$-actin and G9A were as follows: $\beta$-actin forward, 5'-AGCGCGCATCCCCCA AAGTT-3' and $\beta$-actin reverse, 5'-GGGCACGAAGGCTCA TCATT-3'; G9A forward, 5'-AGCCCTGCCCTGAGGATT AC-3' and G9A reverse, 5'-ATGAGCACGCCTGGTTAC ACT-3'. An unpaired Student's t-test was used to compare the expression levels of G9A in HCC tumor tissues and matched non-cancerous tissues. $\mathrm{P}<0.05$ was considered to indicate a statistically significant difference.

GEO HCC gene expression data analysis. The datasets of patients with HCC and corresponding clinical data were downloaded from the publicly available Gene Expression Omnibus (GEO) datasets (www.ncbi.nlm.nih.gov/gds). A total of four independent datasets from GSE6764 (20), GSE14520 (21,22), GSE14323 (23) and GSE50579 (24) were utilized to analyze the expression level of G9A in HCC. For GSE14520, GSE6764 and GSE14323, $\log _{2}$ intensity of probe 202326 were used to represent the expression level of G9A. For GSE50579, $\log _{2}$ intensity of probe A23P214 was used to represent the expression level of G9A. The $\log _{2}$ intensities of probes 207484 and 208786 were used to represent G9A and MAP1LC3B expression, respectively, to perform linear regression analysis in HCC tissues of the GSE14520 testing group $(n=225)$. An unpaired Student's t-test was used to compare the expression levels of G9A in HCC tumor tissues and normal tissues. $\mathrm{P}<0.05$ was considered to indicate a statistically significant difference.

GSEA. A Java program for GSEA (www.broadinstitute.org/gsea) was used to analyze the potential genes affected by increased G9A expression. The data from the GSE14520 testing group of patients with HCC were downloaded and divided into two groups (high and low, determined by comparing with the median value) according to the expression of G9A and Molecular Signatures Database c5 (GO gene sets, 1454 gene sets). Gene sets with a false discovery rate (FDR) $<0.25$ and nominal $\mathrm{P}<0.05$ after 1,000 permutations were regarded as significant enrichment.

Cell culture and reagents. Human HCC cell lines Huh7 and HepG2 were obtained from The China Center for Type Culture Collection (Wuhan, China) and kept in our lab. Huh7 and HepG2 were cultured in RPMI-1640 medium (cat. no. 11875-085, Gibco; Thermo Fisher Scientific, Inc.) and Dulbecco's modified Eagle's medium (cat. no. 11965-084, Gibco; Thermo Fisher Scientific, Inc.) containing 10\% fetal bovine serum (cat. no. 10082147, Gibco; Thermo Fisher Scientific, Inc.), respectively. The cells were cultured at $37^{\circ} \mathrm{C}$ in a humidified atmosphere containing $5 \% \mathrm{CO}_{2}$. G9A inhibitor BIX-01294 (cat. no. B9311; Sigma-Aldrich; Merck KGaA, Darmstadt, Germany) was dissolved in sterilized water and then added to the medium to a final concentration of $5 \mu \mathrm{M}$. Following incubation for 24,48 or $72 \mathrm{~h}$, cells were harvested and analyzed in the following experiments.

Western blotting. Subsequent to treatment, the whole-cell extract was prepared by scraping the Huh7 and HepG2 cells in radioimmunoprecipitation buffer (cat. no, G2002, Servicebio Inc., Woburn, MA, USA). The protein concentrations were determined using a BCA protein assay kit (cat. no. P0011; Beyotime Institute of Biotechnology, Haimen, China). For every sample, $50 \mu \mathrm{g}$ total proteins was used and separated by SDS-PAGE (12\% gels) and transferred onto polyvinylidene fluoride membranes. The membranes were blocked at room temperature with non-fat milk for $1 \mathrm{~h}$ and incubated with primary antibodies $(1: 1,000)$ overnight at $4^{\circ} \mathrm{C}$. Secondary antibodies [goat anti-rabbit (cat. no. 926-32211) or mouse (cat. no. 926-32210) IR Dye 800CW, LI-COR Biosciences, Lincoln, NE, USA] were used to detect binding of the primary antibodies by incubation at room temperature for $50 \mathrm{~min}$. The bands were detected using the Odyssey CLx imaging system (LI-COR Biosciences) and analyzed by Image Studio Software for Odyssey CLx (LI-COR Biosciences). The primary antibodies used in the present study against the following were all 
from Cell Signaling Technology, Inc. (Danvers, MA, USA): $\beta$-actin (cat. no. 4970), GAPDH (cat. no. 2118), MAP1LC3B (cat. no. 2775), G2/mitotic-specific cyclin B1 (cyclin B1; cat. no. 4135) and cyclin-dependent kinase inhibitor $1 \mathrm{~B}$ (p27; cat. no. 2552).

Flow cytometry. Following BIX-01294 treatment, Huh7 and HepG2 cells were trypsinized and washed briefly with PBS once to remove the residual serum and trypsin. For cell cycle analysis, cells were fixed in $1 \mathrm{ml}$ ice-cold $70 \%$ ethanol overnight at $-20^{\circ} \mathrm{C}$. Following fixation, cells were pelleted at $800 \mathrm{x} \mathrm{g}$ at $4^{\circ} \mathrm{C}$ for $5 \mathrm{~min}$, the supernatant was aspirated carefully so as not to lose the pellet. The pellets were briefly washed twice with ice-cold PBS. The cells were resuspended with $500 \mu \mathrm{l}$ propidium iodide (PI)/RNase A solution $(50 \mu \mathrm{g} / \mathrm{ml}$ PI, $100 \mu \mathrm{g} / \mathrm{ml}$ RNase A and $0.1 \%$ Triton X-100 in PBS). The cells were incubated for $20 \mathrm{~min}$ at $37^{\circ} \mathrm{C}$. DNA content was measured using a FACSCalibur instrument (BD Biosciences, Franklin Lakes, NJ, USA), and Modfit LT v3.3 (Verity Software House, Inc., Topsham, ME, USA) was used to analyze cell cycle phase distribution. For Annexin V/PI double staining analysis, following treatment with BIX-01294 as described above, HCC cells were double-stained with Annexin V-FITC and $\mathrm{PI}$ and incubated at room temperature for $5 \mathrm{~min}$ in the dark. A total of $10 \times 10^{4}$ cells from each group were analyzed using a FACSCalibur instrument.

Statistical analysis. Experiments were performed at least 3 times. Results are expressed as the mean \pm standard deviation. Statistically significant differences among the groups were determined by one-way analysis of variance with Tukey's post hoc tests using SPSS 19.0 (IBM Corp., Armonk, NY, USA) and are presented as ${ }^{*} \mathrm{P}<0.05,{ }^{* *} \mathrm{P}<0.01$ and ${ }^{* * *} \mathrm{P}<0.001$. $\mathrm{P}<0.05$ was considered to indicate a statistically significant difference. Linear regression was used to determine the correlation between two variants with GraphPad Prism version 5.01 (GraphPad Software, Inc., La Jolla, CA, USA). The correlation between gene expression and the clinicopathologic features was analyzed by $\chi^{2}$ test. Kaplan-Meier plots were constructed, and a log-rank test was used to evaluate differences in G9A expression levels for overall survival.

\section{Results}

G9A expression is increased in HCC tissues. It has been demonstrated that the expression level of G9A was increased in a number of types of cancer, including HCC (16). First, in the present study the relative mRNA expression level was examined in 14 pairs of HCC tissue samples using RT-qPCR, and identified a significant increase in G9A mRNA expression level in HCC tumor specimens compared with their adjacent non-tumorous liver tissue samples $(\mathrm{P}=0.0196$; Fig. 1A). Subsequently, publicly available microarray datasets were analyzed to observe whether a similar phenomenon may be revealed. A total of four independent HCC microarray datasets containing $\mathrm{HCC}$ and normal liver tissues from the GEO were analyzed, including the GSE14520 training group $(n=43)$ and testing group $(n=445)(21,22)$; and GSE6764 $(n=75)(20)$, GSE14323 $(n=124)(23)$ and GSE50579 $(n=80)(24)$. All four datasets exhibited significantly increased expression levels of G9A mRNA in HCC tumor tissues compared with their non-tumor liver tissues $(\mathrm{P}<0.0001$ in all datasets; Fig. 1B-F). Collectively, these data additionally confirmed that G9A expression level was significantly increased in HCC.

Association of G9A expression with the clinicopathological features of $H C C$. The association between G9A expression and clinicopathological features of HCC with GSE14520 were next analyzed to identify the potential roles of G9A in the pathogenesis of HCC. The samples pooled in the HCC dataset GSE14520 were divided into two groups according to the expression level of G9A in tumor tissues, and examined using a $\chi^{2}$ test. The top 50\% samples with the highest G9A expression were considered the high-expression group, and the other $50 \%$ as the low-expression group. As summarized in Table I, G9A expression was significantly associated with the serum $\alpha$-fetoprotein (AFP) level $(\mathrm{P}=0.009)$. It appeared that patients with a lower expression level of G9A were more likely to exhibit a lower serum AFP level. With the exception of a moderate association between G9A expression and cirrhosis $(\mathrm{P}=0.054)$, there was no significant association between its expression level and the other clinicopathological features (P>0.05; Table I).

Association between G9A expression and survival of patients with $H C C$. To investigate the association between G9A expression and survival of patients with HCC, Kaplan-Meier estimator analysis was used to evaluate the effect of its expression level on the survival of patients with HCC by using the GSE14520 datasets stratified by clinical features included age, sex, active hepatitis B virus status (chronically active viral replication), AFP serum level, nodular type, cirrhosis, tumor size $(>5 \mathrm{~cm}$, large; $\leq 5 \mathrm{~cm}$ small) and various tumor staging methods such as Barcelona Clinic Liver Cancer, Cancer Liver Italian Program or Tumor Node Metastasis classification $(21,22)$. The result of survival analysis demonstrated a weak difference in the survival between patients with multinodular HCC and patients with non-multinodular $\mathrm{HCC}(\mathrm{P}=0.0548$; Fig. 2A). Furthermore, the results of the survival analysis indicated that the survival rates of patients with multinodular HCC whose tumor tissues exhibited an increased G9A expression level was significantly decreased compared with the survival rates of patients with multinodular HCC with a decreased G9A expression level ( $\mathrm{P}=0.0268$; Fig. 2B), and also significantly decreased compared with that of the patients with non-multinodular HCC ( $\mathrm{P}=0.0035$; Fig. 2C). Additionally, there was no marked association between the survival and G9A expression level in patients with non-multinodular HCC ( $\mathrm{P}=0.5124$; Fig. $2 \mathrm{D})$ or HCC patients with any other clinical features (data not shown).

G9A inhibitor represses HCC cell growth. Results of previous studies have suggested that suppression of G9A may inhibit proliferation in numerous types of cancer cell (15-17). To investigate the potential function of G9A in HCC pathogenesis, GSEA using HCC tumor gene profiling data from the GSE14520 group $(n=225)$ was performed. There were 94 gene sets that were significantly upregulated in the 'G9A high' group compared with the 'G9A low' group (FDR $<0.25$ and nominal $\mathrm{P}<0.05)$, among which there were 10 gene sets associated with RNA and DNA processing. These results indicated that 
A

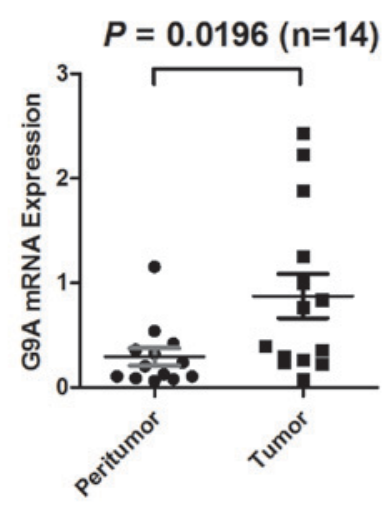

B

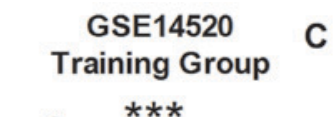

C GSE14520 Testing Group ***

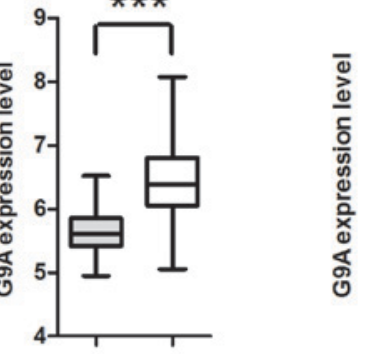


Table I. Association between G9A expression and the clinicopathological features of the hepatocellular carcinoma cases from the GSE14520 dataset.

G9A expression

\begin{tabular}{|c|c|c|c|c|c|}
\hline Characteristics & Case size & High & Low & $\chi^{2}$ value & P-value \\
\hline \multicolumn{6}{|l|}{ Sex } \\
\hline Male & 190 & 98 & 92 & & \\
\hline Female & 30 & 11 & 19 & 2.305 & 0.129 \\
\hline \multicolumn{6}{|c|}{$\alpha$-fetoprotein level, $\mathrm{ng} / \mathrm{ml}$} \\
\hline $\operatorname{High}(>300)$ & 99 & 58 & 41 & & \\
\hline Low $(\leq 300)$ & 118 & 48 & 70 & 6.909 & $0.009^{\mathrm{a}}$ \\
\hline \multicolumn{6}{|l|}{ Age, years } \\
\hline$>50$ & 108 & 51 & 57 & & \\
\hline$\leq 50$ & 114 & 59 & 55 & 0.456 & 0.500 \\
\hline \multicolumn{6}{|l|}{ ALT level, U/l } \\
\hline $\operatorname{High}(>50)$ & 91 & 46 & 45 & & \\
\hline Low $(\leq 50)$ & 129 & 63 & 66 & 0.063 & 0.802 \\
\hline \multicolumn{6}{|l|}{ Tumor size, $\mathrm{cm}$} \\
\hline Large $(>5)$ & 80 & 42 & 38 & & \\
\hline Small $(\leq 5)$ & 139 & 66 & 73 & 0.512 & 0.474 \\
\hline \multicolumn{6}{|l|}{ Multinodular } \\
\hline Yes & 45 & 23 & 22 & & \\
\hline No & 175 & 86 & 89 & 0.055 & 0.814 \\
\hline \multicolumn{6}{|l|}{ Cirrhosis } \\
\hline Yes & 202 & 104 & 98 & & \\
\hline No & 18 & 5 & 13 & 3.716 & 0.054 \\
\hline \multicolumn{6}{|c|}{ Tumor-node-metastasis stage } \\
\hline I & 93 & 46 & 47 & & \\
\hline II & 77 & 36 & 41 & & \\
\hline III & 48 & 25 & 23 & 0.345 & 0.841 \\
\hline \multicolumn{6}{|c|}{ Barcelona clinic liver cancer staging } \\
\hline A & 148 & 69 & 79 & & \\
\hline B & 22 & 12 & 10 & & \\
\hline $\mathrm{C}$ & 28 & 14 & 14 & 0.535 & 0.765 \\
\hline \multicolumn{6}{|c|}{ Cancer liver Italian program staging } \\
\hline 0 & 97 & 42 & 55 & & \\
\hline 1 & 74 & 38 & 36 & & \\
\hline 2 & 35 & 20 & 14 & & \\
\hline 3 & 9 & 5 & 4 & & \\
\hline 4 & 3 & 2 & 1 & & \\
\hline 5 & 1 & 0 & 1 & 4.601 & 0.467 \\
\hline
\end{tabular}

${ }^{\mathrm{a}} \mathrm{G} 9$ A expression was significantly associated with the serum $\alpha$-fetoprotein level $(\mathrm{P}<0.05)$. G9A, euchromatic histone-lysine $\mathrm{N}$-methyltransferase; ALT, alanine aminotransferase.

indicated that G9A may also exhibit the potential to regulate MAP1LC3B expression in HCC tumor tissues.

\section{Discussion}

H3K9 methyltransferase G9A is involved in a number of important developmental events, such as the lineage commitment of stem cells and early embryonic stem cell differentiation $(14,25)$. It has also been demonstrated to be overexpressed in numerous types of cancer, such as breast, prostate, colon, bladder, ovarian, melanoma, lung and liver cancer (16-18,26-28). Despite this, its functions in tumorigenesis require additional investigation. In the present study, its potential functions in the progression of HCC were preliminarily explored, and the association 
A

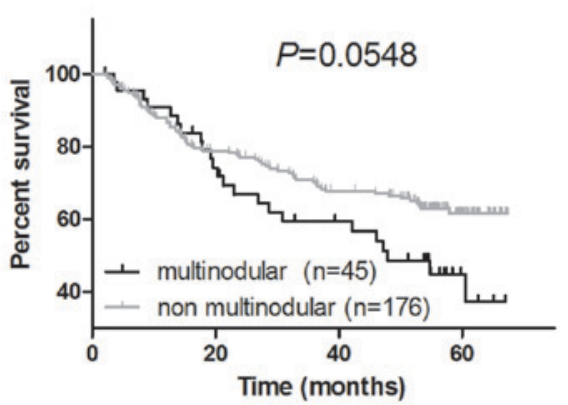

C

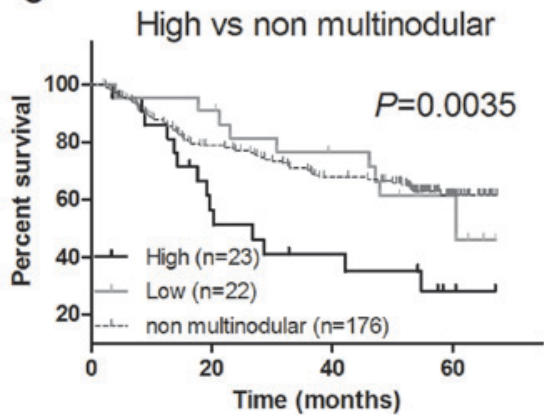

B

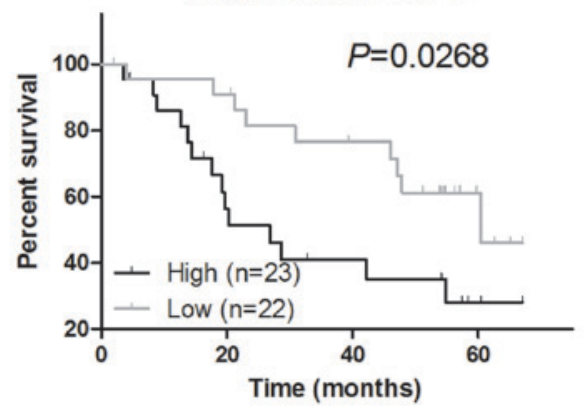

D

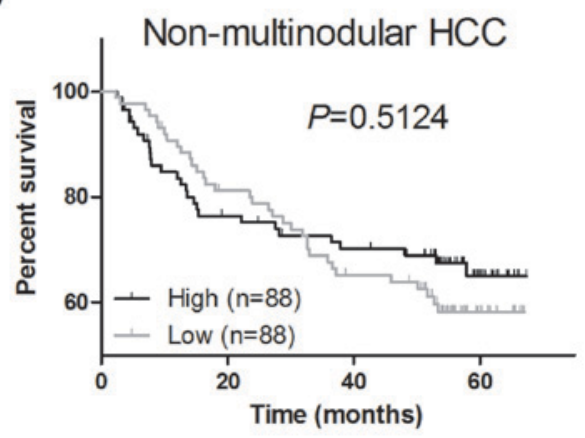

Figure 2. Survival analysis of G9A expression in HCC patients in the GSE14520 dataset. The Kaplan-Meier estimator method was used to estimate survival curves and the log-rank test was used to compare the differences between curves. The top 50\% with the highest G9A expression were considered the 'high-expression' group and the remaining 50\% of samples were the 'low-expression' group. (A) Survival curves between patients with multinodular HCC and patients with non-multinodular HCC. (B) Survival curves for patients with multinodular HCC. (C) Survival curves for patients with multinodular HCC compared with distinct G9A expression levels and patients with non-multinodular HCC. (D) Survival curves for patients with non-multinodular HCC. HCC, hepatocellular carcinoma; G9A, euchromatic histone-lysine N-methyltransferase.

A

\begin{tabular}{ccccc}
\hline & Gene sets name & NES & NOM p-value & FDR q-value \\
\hline 1 & Protein_RNA_complex_assembly & 1.9144 & 0.0020 \\
\hline 2 & RNA_splicingvia_transesterification_reactions & 1.7830 & 0.0524 \\
\hline 3 & RNA_processing & 1.7710 & 0.0019 & 0.0142 \\
\hline 4 & RNA_splicing & 1.7616 & 0.0964 \\
\hline 5 & RNA_binding & 1.7224 & 0.0143 & 0.0189 \\
\hline 6 & DNA_directed_RNA_polymerasell_holoenzyme & 1.6988 & 0.0896 \\
\hline 7 & MRNA_processing_Go_0006397 & 1.6984 & 0.0162 & 0.1190 \\
\hline 8 & DNA_replication & 1.6742 & 0.1461 \\
\hline 9 & MRNA_metabolic_process & 1.6639 & 0.1401 & 0.0101 \\
10 & DNA_dependent_DNA_replication & 1.6307 & 0.1380 \\
\hline
\end{tabular}
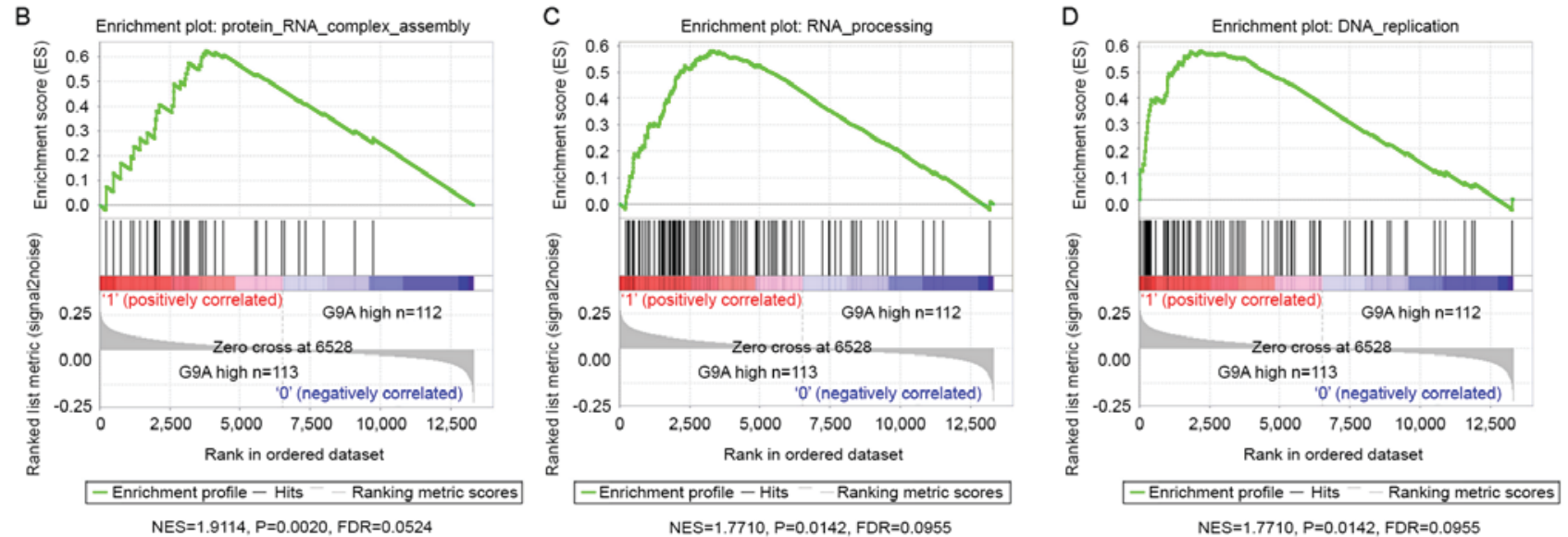

Figure 3. GSEA demonstrates the biological processes modulated by G9A. (A) GSEA analysis of Gene Ontology terms indicated that G9A may regulate gene sets associated with RNA processing and DNA replication. Enrichment plots demonstrating (B) protein RNA complex assembly, (C) RNA processing and (D) DNA replication. GSEA, gene set enrichment analysis; G9A, euchromatic histone-lysine N-methyltransferase; NES, normalized enrichment score; NOM, nominal; FDR, false discovery rate. 


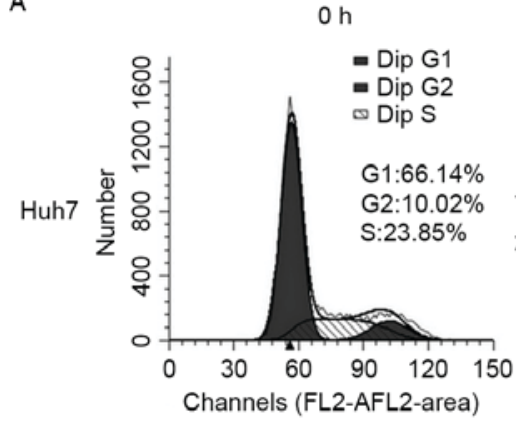

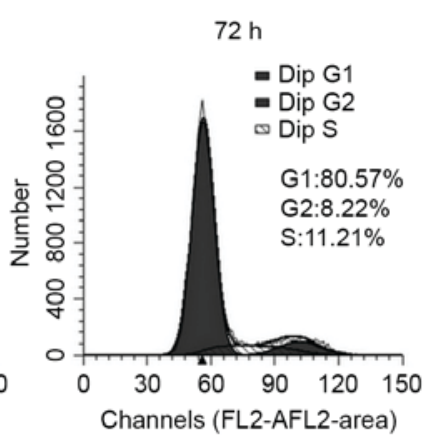

B

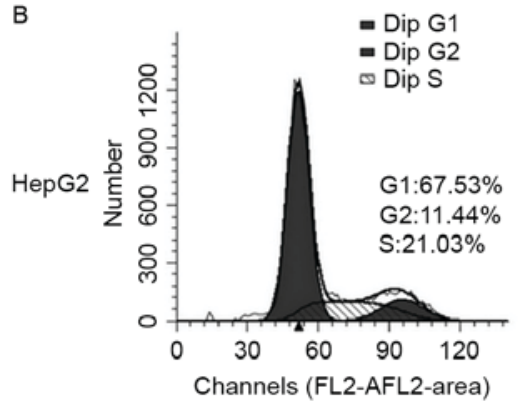

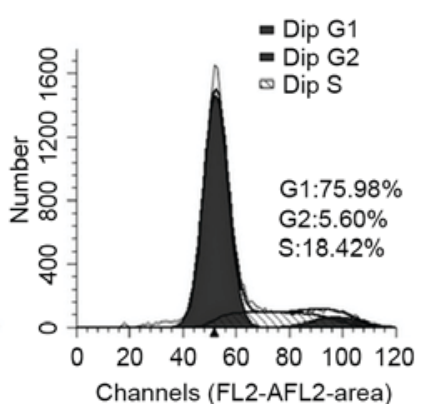
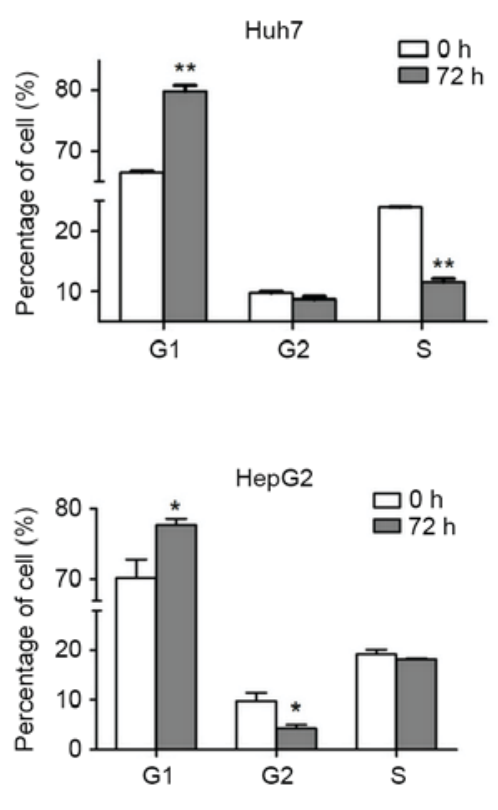

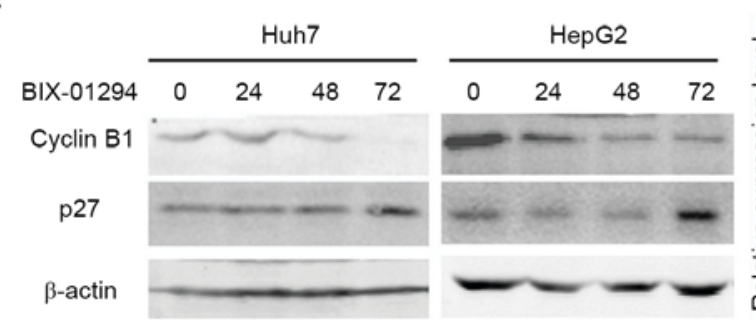

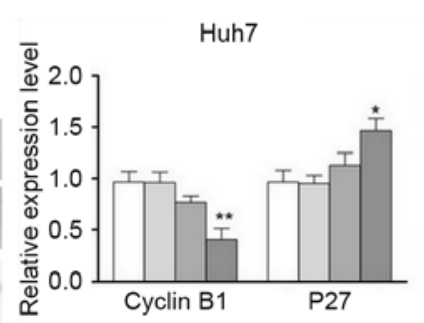

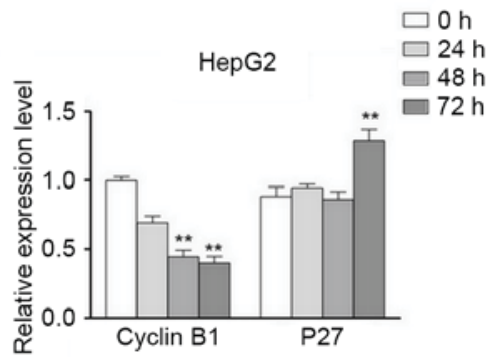

Figure 4. Dysfunction of proliferation of G9A-inhibited HCC cells, and arrest of cells in G1 phase. (A and B) G9A was inhibited in HCC cells for 72 h. Cell cycle distribution was analyzed using flow cytometry. Results are the mean \pm SD of the percentages of G1, S and G2/M phases. (C) Western blotting of cyclin B1 and p27 in HCC cells treated with its specific inhibitor for the indicated time. $\beta$-actin levels are presented as the loading control. Results are the mean $\pm \mathrm{SD}$ of the relative expression level. $0 \mathrm{~h}$ treatment groups compared to the $72 \mathrm{~h}$ treatment groups. ${ }^{*} \mathrm{P}<0.05$ and ${ }^{* *} \mathrm{P}<0.01$ as indicated. G9A, euchromatic histone-lysine N-methyltransferase; SD, standard deviation; p27, cyclin-dependent kinase inhibitor 1B.

between G9A expression and clinicopathological features of HCC were analyzed.

The results of the present study from RT-qPCR analysis of HCC samples and the publicly available microarray datasets, additionally confirmed that G9A was overexpressed in HCC tumor tissues. These results suggested that increased G9A expression was a biomarker of malignant cells. By analyzing the association between G9A expression and clinicopathological features using GSE14520, it was identified that its expression level was significantly associated with serum AFP level, and that the high expression level of G9A may indicate poor prognoses in patients with multinodular HCC. As serum AFP level is a primary tumor serological marker for $\mathrm{HCC}$ diagnosis, it was hypothesized that G9A expression level may be of assistance in diagnosing $\mathrm{HCC}$, and may also have significant prognostic value in HCC.

The increased level of G9A expression in many types of tumor tissue clearly indicated that this molecule may promote the survival of tumor cells (15-17). This assumption had been confirmed by the GSEA analysis in the present study, which indicated that G9A may modulate genes that are associated with RNA processing and DNA replication, suggesting that
G9A was involved in cell proliferation. The results of the present study, and those of a number of previous studies, have demonstrated that G9A inhibition may suppress cell proliferation in HCC cells and numerous other types of cancer cell $(15,16,19)$. As G9A is important for cell proliferation, it is important to consider the crucial role of its primary target, $\mathrm{H} 3 \mathrm{~K} 9 \mathrm{me} 2$. A previous study indicated that G9A and H3K9me2 were involved in R-loop formation, efficient transcriptional termination and gene post-transcriptional regulation (29). Therefore, it was hypothesized that G9A served a crucial role in cell proliferation, which may be involved in its role in tumorigenesis.

Autophagy is an evolutionarily conserved 'self-eating' process that is characterized by the formation of autophagosomes (30). MAP1LC3B is essential for membrane elongation and closure, which is the key molecular event in autophagy (30). It has been demonstrated experimentally that G9A is an epigenetic regulator for MAP1LC3B expression, and that G9A inhibition may induce autophagy-associated cell death $(15,19,31)$. The present study demonstrated that G9A inhibition may increase MAP1LC3B expression in Huh7 and HepG2 cells. Furthermore, by analyzing the publicly available datasets in the GSE14520 


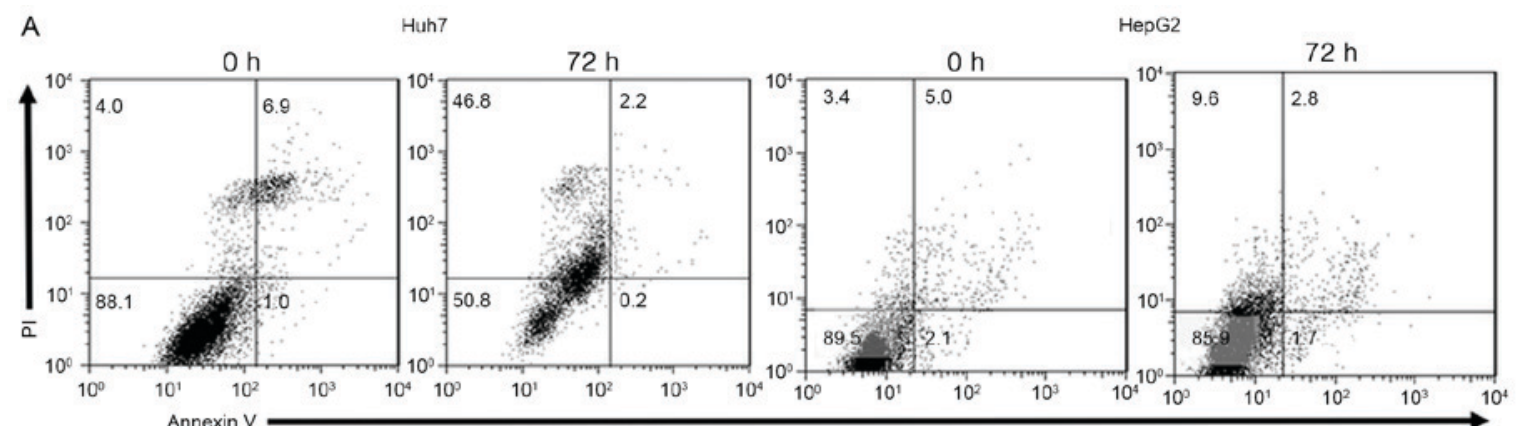

B

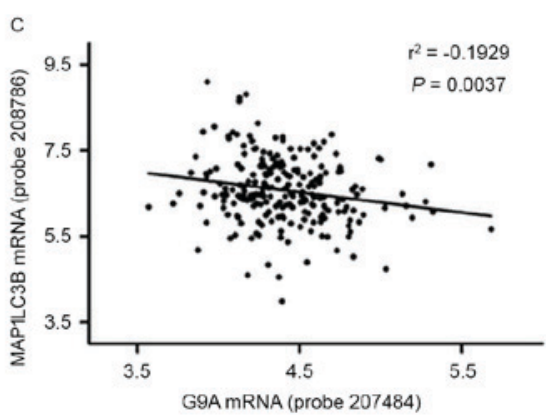

Figure 5. G9A inhibition increased MAP1LC3B expression in HCC cells. (A) Annexin V-fluorescein isothiocyanate/PI double staining of BIX-01294-treated HCC cells were analyzed by flow cytometry analysis. Numbers indicate the percentage of cells in each quadrant. (B) Western blot analysis of MAP1LC3B expression in HCC cells treated with BIX-01294 for 24, 48 and $72 \mathrm{~h}$. (C) Inverse association between G9A and MAP1LC3B expression in HCC tissues in the GSE14520 testing group $(n=225)\left(r^{2}=-0.1929, P=0.0037\right)$. MAP1LC3B, microtubule-associated protein light chain $3 \beta$; PI, propidium iodide; HCC, hepatocellular carcinoma; G9A, euchromatic histone-lysine N-methyltransferase.

testing group, a significant inverse association between G9A and MAP1LC3B expression levels was identified. These results provide evidence that G9A may have the potential to regulate MAP1LC3B expression in HCC tumor tissues.

Despite increased G9A expression being demonstrated as being crucial for tumor cell proliferation and autophagy-induced cell death (15-17) its clinical significance in these types of cancer remains obscure. The present study provided results that the high expression of G9A may serve as an indicator for poor prognosis in multinodular $\mathrm{HCC}$, and additionally confirmed an association between G9A and cell proliferation and MAP1LC3B expression in HCC cells. The results also demonstrated that G9A was involved in the pathogenesis of HCC, and may also serve as a potential target for HCC therapy. As aforementioned, its importance was not only confined to tumor cells. It is vital to disable G9A specifically in tumor cells without affecting normal cells during cancer therapy. The underlying molecular mechanisms of its expression remain obscure and require elucidation, which would assist in understanding the origin of G9A-associated cancer, and the developmental events in which G9A is involved.

In conclusion, the present study investigated the association between G9A expression level and the clinicopathological features of HCC by using publicly available datasets, and identified that G9A expression was associated with cell proliferation and autophagy in HCC cells. These results provide novel evidence for additional understanding of the crucial role of G9A in the tumorigenesis of HCC.

\section{Acknowledgements}

Not applicable.

\section{Funding}

The present study was supported by the Natural Science Foundation of Hubei Province in China (grant nos. 2012FFB04316 and 2013CFB255), The Incubator Project of Renmin Hospital Wuhan University (grant no. 2013RMFH008), and the National Natural Science Foundation of China (grant no. 31300609).

\section{Availability of data and materials}

The datasets used and/or analyzed during the current study are available from the corresponding author on reasonable request.

\section{Author's contributions}

JQ and QL conducted the majority of the experiments. ZZ, PW, YJ and YH collected the samples. TL contributed to data analysis and manuscript drafting. XJ and QZ contributed to Flow Cytometry. JQ and LC contribute to design and manuscript.

\section{Ethics approval and consent to participate}

The research protocol was approved by Wuhan University School of Basic Medical Sciences Ethics Committee. Informed written consent was obtained from all participants involved in the study.

\section{Consent for publication}

Informed written consent was obtained from all participants involved in the study. 


\section{Competing interests}

The authors declare that they have no competing interests.

\section{References}

1. Rodriguez-Paredes M and Esteller M: Cancer epigenetics reaches mainstream oncology. Nat Med 17: 330-339, 2011.

2. Fraga MF, Ballestar E, Villar-Garea A, Boix-Chornet M, Espada J, Schotta G, Bonaldi T, Haydon C, Ropero S, Petrie K, et al: Loss of acetylation at Lys16 and trimethylation at Lys20 of histone $\mathrm{H} 4$ is a common hallmark of human cancer. Nat Genet 37: 391-400, 2005.

3. Wood LD, Parsons DW, Jones S, Lin J, Sjöblom T, Leary RJ, Shen D, Boca SM, Barber T, Ptak J, et al: The genomic landscapes of human breast and colorectal cancers. Science 318 : $1108-1113,2007$

4. Jemal A, Bray F, Center MM, Ferlay J, Ward E and Forman D: Global cancer statistics. CA Cancer J Clin 61: 69-90, 2011.

5. Forner A, Llovet JM and Bruix J: Hepatocellular carcinoma. Lancet 379: 1245-1255, 2012.

6. Fujimoto A, Totoki Y, Abe T, Boroevich KA, Hosoda F, Nguyen $\mathrm{HH}$, Aoki M, Hosono $\mathrm{N}$, Kubo M, Miya F, et al: Whole-genome sequencing of liver cancers identifies etiological influences on mutation patterns and recurrent mutations in chromatin regulators. Nat Genet 44: 760-764, 2012.

7. Gao SB, Xu B, Ding LH, Zheng QL, Zhang L, Zheng QF, Li SH, Feng ZJ, Wei J, Yin ZY, et al: The functional and mechanistic relatedness of EZH2 and menin in hepatocellular carcinoma. J Hepatol 61: 832-839, 2014.

8. Shinkai Y and Tachibana M: H3K9 methyltransferase G9a and the related molecule GLP. Genes Dev 25: 781-788, 2011.

9. Dawson MA and Kouzarides T: Cancer epigenetics: From mechanism to therapy. Cell 150: 12-27, 2012.

10. Maze I, Covington HE III, Dietz DM, LaPlant Q, Renthal W, Russo SJ, Mechanic M, Mouzon E, Neve RL, Haggarty SJ, et al: Essential role of the histone methyltransferase G9a in cocaine-induced plasticity. Science 327: 213-216, 2010.

11. Thomas LR, Miyashita H, Cobb RM, Pierce S, Tachibana M, Hobeika E, Reth M, Shinkai Y and Oltz EM: Functional analysis of histone methyltransferase g9a in B and T lymphocytes. J Immunol 181: 485-493, 2008.

12. Katoh K, Yamazaki R, Onishi A, Sanuki R and Furukawa T: G9a histone methyltransferase activity in retinal progenitors is essential for proper differentiation and survival of mouse retinal cells. J Neurosci 32: 17658-17670, 2012.

13. Ueda J, Ho JC, Lee KL, Kitajima S, Yang H, Sun W, Fukuhara N, Zaiden N, Chan SL, Tachibana M, et al: The hypoxia-inducible epigenetic regulators Jmjd1a and G9a provide a mechanistic link between angiogenesis and tumor growth. Mol Cell Biol 34: 3702-3720, 2014.

14. Chen X, Skutt-Kakaria K, Davison J, Ou YL, Choi E, Malik P, Loeb K, Wood B, Georges G, Torok-Storb B and Paddison PJ: G9a/GLP-dependent histone H3K9me2 patterning during human hematopoietic stem cell lineage commitment. Genes Dev 26: 2499-2511, 2012.

15. Ke XX, Zhang D, Zhu S, Xia Q, Xiang Z and Cui H: Inhibition of H3K9 methyltransferase G9a repressed cell proliferation and induced autophagy in neuroblastoma cells. PloS One 9: e106962, 2014.

16. Huang J, Dorsey J, Chuikov S, Pérez-Burgos L, Zhang X, Jenuwein T, Reinberg D and Berger SL: G9a and Glp methylate lysine 373 in the tumor suppressor p53. J Biol Chem 285: 9636-9641, 2010.

17. Kondo Y, Shen L, Suzuki S, Kurokawa T, Masuko K, Tanaka Y, Kato H, Mizuno Y, Yokoe M, Sugauchi F, et al: Alterations of DNA methylation and histone modifications contribute to gene silencing in hepatocellular carcinomas. Hepatol Res 37: 974-983, 2007.
18. Chen MW, Hua KT, Kao HJ, Chi CC, Wei LH, Johansson G, Shiah SG, Chen PS, Jeng YM, Cheng TY, et al: H3K9 histone methyltransferase G9a promotes lung cancer invasion and metastasis by silencing the cell adhesion molecule Ep-CAM. Cancer Res 70: 7830-7840, 2010.

19. Kim Y, Kim YS, Kim DE, Lee JS, Song JH, Kim HG, Cho DH, Jeong SY, Jin DH, Jang SJ, et al: BIX-01294 induces autophagy-associated cell death via EHMT2/G9a dysfunction and intracellular reactive oxygen species production. Autophagy 9: 2126-2139, 2013.

20. Wurmbach E, Chen YB, Khitrov G, Zhang W, Roayaie S, Schwartz M, Fiel I, Thung S, Mazzaferro V, Bruix J, et al: Genome-wide molecular profiles of $\mathrm{HCV}$-induced dysplasia and hepatocellular carcinoma. Hepatology 45: 938-947, 2007.

21. Roessler S, Long EL, Budhu A, Chen Y, Zhao X, Ji J, Walker R, Jia HL, Ye QH, Qin LX, et al: Integrative genomic identification of genes on $8 p$ associated with hepatocellular carcinoma progression and patient survival. Gastroenterology 142: 957-966, 2012.

22. Roessler S, Jia HL, Budhu A, Forgues M, Ye QH, Lee JS, Thorgeirsson SS, Sun Z, Tang ZY, Qin LX and Wang XW: A unique metastasis gene signature enables prediction of tumor relapse in early-stage hepatocellular carcinoma patients. Cancer Res 70: 10202-10212, 2010

23. Mas VR, Maluf DG, Archer KJ, Yanek K, Kong X, Kulik L, Freise CE, Olthoff KM, Ghobrial RM, McIver P and Fisher R: Genes involved in viral carcinogenesis and tumor initiation in hepatitis $\mathrm{C}$ virus-induced hepatocellular carcinoma. Mol Med 15: 85-94, 2009.

24. Neumann O, Kesselmeier M, Geffers R, Pellegrino R, Radlwimmer B, Hoffmann K, Ehemann V, Schemmer P, Schirmacher P, Lorenzo Bermejo J and Longerich T: Methylome analysis and integrative profiling of human HCCs identify novel protumorigenic factors. Hepatology 56: 1817-1827, 2012.

25. Melcer S, Hezroni H, Rand E, Nissim-Rafinia M, Skoultchi A, Stewart CL, Bustin M and Meshorer E: Histone modifications and lamin A regulate chromatin protein dynamics in early embryonic stem cell differentiation. Nat Commun 3: 910 , 2012.

26. Kondo Y, Shen L, Ahmed S, Boumber Y, Sekido Y, Haddad BR and Issa JP: Downregulation of histone H3 lysine 9 methyltransferase G9a induces centrosome disruption and chromosome instability in cancer cells. PloS One 3: e2037, 2008.

27. Cho HS, Kelly JD, Hayami S, Toyokawa G, Takawa M, Yoshimatsu M, Tsunoda T, Field HI, Neal DE, Ponder BA, et al: Enhanced expression of EHMT2 is involved in the proliferation of cancer cells through negative regulation of SIAH1. Neoplasia 13: 676-684, 2011

28. Vedadi M, Barsyte-Lovejoy D, Liu F, Rival-Gervier S, Allali-Hassani A, Labrie V, Wigle TJ, Dimaggio PA, Wasney GA, Siarheyeva A, et al: A chemical probe selectively inhibits G9a and GLP methyltransferase activity in cells. Nat Chem Biol 7: 566-574, 2011.

29. Skourti-Stathaki K, Kamieniarz-Gdula K and Proudfoot NJ: R-loops induce repressive chromatin marks over mammalian gene terminators. Nature 516: 436-439, 2014.

30. Barth S, Glick D and Macleod KF: Autophagy: Assays and artifacts. J Pathol 221: 117-124, 2010.

31. Artal-Martinez de Narvajas A, Gomez TS, Zhang JS, Mann AO, Taoda Y, Gorman JA, Herreros-Villanueva M, Gress TM, Ellenrieder V, Bujanda L, et al: Epigenetic regulation of autophagy by the methyltransferase G9a. Mol Cell Biol 33: 3983-3993, 2013.

This work is licensed under a Creative Commons Attribution-NonCommercial-NoDerivatives 4.0 International (CC BY-NC-ND 4.0) License. 